\title{
Evaluation of Air Textured Warp Yarn Samples with TOPSIS method According to Quality Standards
}

\author{
Umutgül Kaplan, Eren Özceylan \\ Gaziantep University, Industrial Engineering Department, Gaziantep, 27100, Turkey
}

\begin{abstract}
.
The air textured warp yarn; produced from polyester fiber, is used as warp yarn in carpet weaving industry and is one of the yarns that form the floor of the carpet. Air textured warp yarn; that does not reflect the quality values, will cause elongation, shortening, stretching, shrinkage, irregularity problems in the carpet, during or after weaving process. Since these defects occur on the warp yarn, that forms the length of the carpet, directly affect the quality of carpet to be produced, therefore the purpose of the production in the companies producing this yarn, is based on the philosophy of producing quality products, before making a profit. For these reasons; certain criteria, determining the quality yarn, were identified during the production of air textured warp yarn, and standard production values were assigned, depending on those values. In this paper 649 samples of 800 Denier air-jet textured yarn subjected to a series of strength tests with the physical properties of the yarn. Tested yarn properties are count, elongation, shrinkage, tenacity, RKM (reisskilometer), force in kilograms. All tested properties of the yarns are ranked by TOPSIS method, which is a multicriteria decision-making method, based on certain weights. As a result all samples, from best to worst, shown to the decision-maker, to try to help which sample will be used in the next step of if a classification will be defined for quality.
\end{abstract}

Keywords: Multi-criteria decision-making, TOPSIS, Air-jet textured warp yarn, Textile industry, Quality control)

\section{Introduction}

Considering the development degree of the businesses, it is seen that, the continuity of competiveness is one of the main conditions of the principle of making profit and ensuring sustainability. Providing quality product and service production, accordance to customers' needs, expectations and requests, is one of the main conditions of competiveness.

Yarn is used every branch of textile industry, except for non-woven. Because of this reason, producing high quality of yarn groups, used as raw material in the production process, increases market share of producers as it is protecting interests of consumers. Thus producers get a chance to appeal wider audience. Companies, producing quality yarn groups, can increase their prefer ability and easily adapt heightened competition with providing the facts 
of quality, such as standardization, convenience, adaptation, innovation, optimum cost and satisfaction.

The air textured warp yarn; produced from POY (Polly Oriented Polyester Yarn) and used as warp yarn in the carpet weaving industry, that does not reflect the quality values; cause defects in the carpet, during or after the weaving process. Warp and weft yarns are two sets of yarns, used as raw material in weaving process of a carpet. Warp yarn is the set of yarns stretched in a place on a loom, before the interworking of weft yarns during the weaving process. It refers to yarn running lengthwise between weft yarns of a finished woven carpet. (htt)

POY (Partially Oriented Yarn), refers to multifilament and only partially stretched yarn, cannot. POY is generally lower tenacity and less uniform due to its polymer structure and it cannot be used directly in textile. It is textured to make it usable and add bulk to the yarn. This type of yarn can be used a base for the production of all types of textured yarn (ATY, DTY and ITY). Textured POY can be used in draw warping, for weaving and warp knitting of fabrics. (Özkan \& Babaarslan, 2008)

In the production of warp yarn, using air-jet texturing process, which is a thermo mechanical texturing method, transforms flat multi-filament yarns with a spun like a character. Air-jet texturing mechanically alters the parallel arrangement of the synthetic filaments within the yarn, transforming them into a bulky, spun yarn like structure.

There are different types of machine made carpets with different qualities are manufactured for various applications. Using high quality yarns as raw material for carpet and quality control at the manufacturing process with standard carpet maintenance methods, lead better quality and further durability for the product.

Air textured warp yarn forms the length of the carpet and directly affect the quality of the carpet to be produce. Any yarn that does not reflect the quality values will cause will cause elongation, shortening, stretching, shrinkage, irregularity problems in the carpet, during or after weaving process. Thus causes negative feedback from the customer, such as complaiments, payment fault and order cancelition.

In the production of Air Textured Yarn, companies that aim standard quality at every process of the production line, from raw material to finished good, primarily preferred from the carpet manufacturers.

Customers give specifications to producers, such as denier, number of filaments, crimp properties, nodes per unit length, minimum strength and elasticity required. Anything deviating from the specification shall be rejected as poor quality. There are three main factors affecting the various properties of ATY, which are machine parameter, parent yarn conditions and process parameters. Under the same conditions of those three factors, properties of yarn determined by the instability, linear density and strength, together with structural properties. The effects of those parameters on the final yarn properties can be investigated with linear density, instability and strength tests. As the results of those tests, a comparison can be made between test parameters and standard quality values. Thus provides that if the sample reflects the quality values, and avoiding yarn faults (Sreenivasamurty \& Prushothama, 2017). 
Making a classification about quality and comparing yarn samples with the standard quality parameters can be a multi criteria decision-making problem for yarn producers in textile industry.

Various MCDM methods, namely data envelopment analysis (DEA), order weighted averaging (OWA), analytic hierarchy process (AHP) and technique for order preference by similarity to ideal solutions (TOPSIS) have been successfully used to solve multi-criteria decision problems, mostly occurs at manufacturing process in textile industry and about industrial issues of the sector.

About selection of navel rotor spinning machine, that directly influences quality parameters of final yarn for denim fabric, Majumbarand et al studied with AHP and TOPSIS method, to determine the weights of decision criteria and finally to rank the navels was elicited from the relative closeness (Majumbar, Kaplan, \& Göktepe, 2010).

Saeidi et al developed a new application of data envelopment analysis (DEA), for ranking given group of woven fabric defects in textile manufacturing (Saeidi, Amin, Raissi, \& Gattoufi, 2013).

Order weighted operation (OWA) model and data envelopment analysis (DEA) are applied for another fabric defects problem and Saeidi et al presented DEA approach to rank defects from the most to the least important and introduced a new method to prioritize the observed defects using the OWA operator (Saeidi, Oukil, \& Amin, 2015).

Acar et al used TOPSIS is used as a multi criteria decision making method for sustainable manufacturing performance of a company, from a corporate group in textile industry, to rank manufacturing performance in related years (Acar, Kilıç, \& Güner, 2015).

Subramaniya, et al used TOPSIS method to identify a certain 'Critical Success Factors' approach to increase agility level in textile industry. (Subramaniya, Dev, \& SenthilKumar, 2017).

Recently researchers used TOPSIS for alternative ranking and optimal solutions to solve critical and practical problems in textile sector. Bathrinath et al aimed to recognize and examine the possible risks in textile industry that create accidents and critical alternative for affecting industrial performance with using AHP and TOPSIS method (Bathrinath, Bhalaji, \& Saravanasankar, 2020).

In literature, althougt different MCDM methods used to solve related problems in textile industry, but as it is seen above, there is no study about air textured yarn with the criteria affecting quality.

In this study, data from the quality conrol reports of a company are analyzed and TOPSIS method performed to rank yarn samples from best to worst and make a classification for quality.

\section{Material and Method}

Data is selected from a quality conrol department report of a firm built in Gaziantep. The firm is producing Monofilament Lanscape, Sport Type Grass Yarn, and Air Texture Warp Yarn 
and Fibrillated PP Replacement in $25.000 \mathrm{~m}^{2}$ production plant . Data in the report of the firm six months production period are used as a material in this study.

In this paper 649 samples of 800 Denier air-jet textured yarn, are randomly selected from production line and subjected to a series of strength tests, which are heat resistance test, shrinkage test and tensile test, from the quality contol manager of the firm. Heat resistance test procedures are performed to measure the heat resistance and changings of synhetic products after exposure to certain temperatures. Shrinkage tests of the yarns made with silicon oil by the termo fisher shrinkage test application. Elongation ratio defined with elongation test and the physical properties of the yarn, that are count,tenacity, breaking force and breaking kilometer, are determined by the strength tests of the yarn with an advanced extensometer device and ZwickRoell test sofware named TestXpert . Table 1 shows the terminology of yarn quality parameters (criteria).

Table 1: Yarn quality criteria

\begin{tabular}{|l|l|}
\hline Count & Count is expressed as the length per unit mass (denier). \\
\hline Elongation & $\begin{array}{l}\text { The ratio of extension of a specimen to its initial length, } \\
\text { expressed as a percentage. }\end{array}$ \\
\hline Shrinkage & $\begin{array}{l}\text { The decrease in length of a specimen caused by a specified } \\
\text { treatment, expressed as a percentage of the length of the } \\
\text { untreated test specimen. The lengths are measured before } \\
\text { and during or after treatment under specified tensions. }\end{array}$ \\
\hline Tenacity (denier strength) & It is the breaking strength per denier (gr/denier). \\
\hline RKM (breaking kilometer) & RKM is the abbreviation of resistance per kilometer. \\
\hline Breaking force & $\begin{array}{l}\text { The maximum force aplied to a test specimen carried to } \\
\text { rupture during a tensile test. }\end{array}$ \\
\hline
\end{tabular}

After all testing procedures completed, tested yarn properties are defined as five criteria for TOPSIS method, which are count, elongation, shrinkage, tenacity, RKM(reisskilometer), breaking force and all samples are listed as alternatives. To rank the 649 samples, TOPSIS method, which is deescribed below, is used.

TOPSIS is short abservation of Tecnique for Order Preference by Similarity to ideal Solution and it's developed by Hwang and Yoon in 1981 (Hwang \& Yoon, 1981). It is based on the concept that chosen alternative should be at the shortest distance from the positive ideal solution adn longest distance to the negative ideal solution. TOPSIS can be implemented in six steps (Shih, Shyur, \& Lee, 2007). Table 2 to Table 8 enumartes the model algarithm steps of TOPSIS in the case study.

In the first step of TOPSIS method, evaluaition matrix is built by listing criterions vertically and alternative horizontally, shown in Equation (1). 


$$
A_{i j}=\left[\begin{array}{cccc}
a_{11} & a_{12} & \ldots & a_{1 n} \\
a_{21} & a_{22} & \ldots & a_{2 n} \\
\cdot & & & \cdot \\
\cdot & & & \cdot \\
\cdot & & & \cdot \\
a_{m 1} & a_{m 2} & \ldots & a_{m n}
\end{array}\right]
$$

Seccond step consists to calculate normalized ratings, by dividing each center values by the norm of total outcome vector in order to non-dimensionalize the center values in evaluation matrix and shown in Equation 2.

$$
\begin{gathered}
r_{i j}=\frac{a_{i j}}{\sqrt{\sum_{k=1}^{m} a_{k j}^{2}}} \\
R_{i j}=\left[\begin{array}{cccc}
r_{11} & r_{12} & \ldots & r_{1 n} \\
r_{21} & r_{22} & \ldots & r_{2 n} \\
\cdot & & & \cdot \\
\cdot & & & \cdot \\
\cdot & & & \cdot \\
r_{m 1} & r_{m 2} & \ldots & r_{m n}
\end{array}\right]
\end{gathered}
$$

The normalized decision matrix is converted to weighted normalized matrix, in third step and the structure of weighted normalized decision matrix is shown in Equation (3). The normalized matrix are multiplied by its associated weights $\left(w_{i}\right)\left(\sum_{i=1}^{n} w_{i}=1\right)$.

$$
V_{i j}=\left[\begin{array}{cccc}
w_{1} r_{11} & w_{2} r_{12} & \ldots & w_{n} r_{1 n} \\
w_{1} r_{21} & w_{2} r_{22} & \ldots & w_{n} r_{2 n} \\
\cdot & & & \cdot \\
\cdot & & & \cdot \\
\cdot & & & \cdot \\
w_{1} r_{m 1} & w_{2} r_{m 2} & \ldots & w_{n} r_{m n}
\end{array}\right]
$$

Positive and negative ideal solutions are built in forth step to compare the alternatives with each other, the construction of this step is shown in Equation (4) and Equation (5).

$$
A^{*}=\left\{\left(\max _{i} v_{i j} \mid j \in J\right),\left(\min _{i} v_{i j} \mid j \in J^{\prime}\right\}\right.
$$




$$
\begin{gathered}
A^{*}=\left\{v_{1}^{*}, v_{2}^{*}, \ldots, v_{n}^{*}\right\} \\
A^{-}=\left\{\left(\min _{i} v_{i j} \mid j \in J\right),\left(\max _{i} v_{i j} \mid j \in J^{\prime}\right\}\right. \\
A^{-}=\left\{v_{1}^{-}, v_{2}^{-}, \ldots, v_{n}^{-}\right\}
\end{gathered}
$$

After determining the positive and negative solutions, the Euclidian distances between each of the alternatives and the positive ideal soltion are calculated as shown in Equation (6) and Equation (7)..

$$
\begin{aligned}
& S_{i}^{*}=\sqrt{\sum_{j=1}^{n}\left(v_{i j}-v_{j}^{*}\right)^{2}} \\
& S_{i}^{-}=\sqrt{\sum_{j=1}^{n}\left(v_{i j}-v_{j}^{-}\right)^{2}}
\end{aligned}
$$

Finally, these distances are transformed into a single metric called relative closeness to the ideal solution with Equation (8). All the alternatives then arranged in descending order according to the value of their closeness index. The alternative, at the top of the list is the

\begin{tabular}{|c|c|c|c|c|c|c|}
\hline Product sample & $\mathrm{C} 1$ & $\mathrm{C} 2$ & C3 & $\mathrm{C} 4$ & $\mathrm{C5}$ & C6 \\
\hline & Count & Elongation & Shrinkage & Tenacity & RKM & Breaking force \\
\hline A1 & 787 & 11.0 & 8.9 & 4,0 & 36.52 & 3.23 \\
\hline $\mathrm{A} 2$ & 820 & 14.5 & 8.8 & 4,6 & 40.37 & 3.71 \\
\hline A3 & 800 & 12.5 & 9.5 & 4,4 & 39.45 & 3.54 \\
\hline A4 & 823 & 13.1 & 9.1 & 4,4 & 38.31 & 3.54 \\
\hline A5 & 827 & 12.5 & 9.7 & 4,3 & 36.94 & 3.53 \\
\hline . & & & & & & \\
\hline A617 & 860 & 24.4 & 7.7 & 4.4 & 36.46 & 3.49 \\
\hline . & & & & & & \\
\hline A645 & 829 & 13.3 & 7.2 & 4.2 & 36.50 & 3.39 \\
\hline A646 & 822 & 13.0 & 7.5 & 4.2 & 36.50 & 3.37 \\
\hline A647 & 831 & 11.9 & 8.2 & 3.9 & 33.22 & 3.10 \\
\hline
\end{tabular}
most preferred one.

$$
C_{i}^{*}=\frac{S_{i}^{-}}{S_{i}^{-}+S_{i}^{*}}
$$

Table 2: Decision matrix 
3rd International Conference on Research in

ICRBME

Business, Management and Economics

27-29 November 2020

Dublin, Republic of Ireland

\begin{tabular}{|l|l|l|l|l|l|l|}
\hline A648 & 827 & 11.0 & 8.2 & 3.8 & 32.88 & 3.05 \\
\hline A649 & 830 & 12.4 & 8.0 & 4.2 & 36.00 & 3.36 \\
\hline
\end{tabular}

Table 3: Normalized decision matrix

\begin{tabular}{|l|l|l|l|l|l|l|}
\hline Product sample & C1 & C2 & C3 & C4 & C5 & C6 \\
\hline A1 & 0.0370 & 0.0282 & 0.0398 & 0.0373 & 0.0393 & 0.0376 \\
\hline A2 & 0.0385 & 0.0372 & 0.0394 & 0.0429 & 0.0435 & 0.0432 \\
\hline A3 & 0.0376 & 0.0321 & 0.0425 & 0.0410 & 0.0425 & 0.0412 \\
\hline A4 & 0.0387 & 0.0336 & 0.0407 & 0.0410 & 0.0413 & 0.0412 \\
\hline A5 & 0.0388 & 0.0321 & 0.0434 & 0.0401 & 0.0398 & 0.0399 \\
\hline A617 & & & & & & \\
\hline A645 & 0.0404 & 0.0627 & 0.0345 & 0.0410 & 0.0393 & 0.0406 \\
\hline A646 & & & & & & \\
\hline A647 & 0.0389 & 0.0342 & 0.0322 & 0.0391 & 0.0393 & 0.0395 \\
\hline A648 & 0.0386 & 0.0334 & 0.0336 & 0.0391 & 0.0393 & 0.0392 \\
\hline A649 & 0.0390 & 0.0306 & 0.0367 & 0.0363 & 0.0358 & 0.0361 \\
\hline & 0.0388 & 0.0282 & 0.0367 & 0.0354 & 0.0354 & 0.0355 \\
\hline
\end{tabular}

Table 4: Weighted normalized decision matrix

\begin{tabular}{|l|l|l|l|l|l|l|}
\hline Product sample & C1 & C2 & C3 & C4 & C5 & C6 \\
\hline A1 & 0.0055 & 0.0042 & 0.0100 & 0.0093 & 0.0039 & 0.0038 \\
\hline A2 & 0.0058 & 0.0056 & 0.0098 & 0.0107 & 0.0043 & 0.0043 \\
\hline A3 & 0.0056 & 0.0048 & 0,0106 & 0.0102 & 0.0042 & 0.0041 \\
\hline A4 & 0.0058 & 0,0050 & 0,0102 & 0.0102 & 0.0041 & 0.0041 \\
\hline A5 & 0.0058 & 0,0048 & 0,0109 & 0.0100 & 0.0040 & 0.0040 \\
\hline$\cdot$ & & & & & & \\
\hline A617 & 0.0061 & 0.0094 & 0.0086 & 0.0102 & 0.0039 & 0.0041 \\
\hline. & & & & & & \\
\hline A645 & 0.0058 & 0.0051 & 0.0081 & 0.0098 & 0.0039 & 0.0039 \\
\hline A646 & 0.0058 & 0.0050 & 0.0084 & 0.0098 & 0.0039 & 0.0039 \\
\hline A647 & 0,0059 & 0.0046 & 0.0092 & 0.0091 & 0.0036 & 0.0036 \\
\hline A648 & 0,0058 & 0.0042 & 0.0092 & 0.0089 & 0.0035 & 0.0036 \\
\hline A649 & 0,0058 & 0.0048 & 0.0089 & 0,0098 & 0.0039 & 0,0039 \\
\hline
\end{tabular}


Table 5: Calculation of positive and negative ideal solution

\begin{tabular}{|l|l|l|l|l|l|l|}
\hline & C1 & C2 & C3 & C4 & C5 & C6 \\
\hline$A^{*}$ & 0.0063 & 0.0424 & 0.0136 & 0.0133 & 0.0058 & 0.0053 \\
\hline$A^{-}$ & 0.0054 & 0.0040 & 0.0068 & 0.0082 & 0.0032 & 0.0033 \\
\hline
\end{tabular}

Table 6: The distance of each alternative to the positive ideal solution

\begin{tabular}{|l|l|l|l|l|l|l|l|l|}
\hline Product sample & C1 & C2 & C3 & C4 & C5 & C6 & $S_{i}^{*}$ \\
\hline A1 & 37.2209 & 21.6844 & 0.0245 & 0.0044 & 0.0921 & 0.0100 & 59.0364 & 7.6835 \\
\hline A2 & 37.2181 & 21.6719 & 0.0245 & 0.0042 & 0.0919 & 0.0099 & 59.0205 & 7.6825 \\
\hline A3 & 37.2198 & 21.6790 & 0.0243 & 0.0043 & 0.0919 & 0.0100 & 59.0293 & 7.6831 \\
\hline A4 & 37.2178 & 21.6769 & 0.0244 & 0.0043 & 0.0920 & 0.0100 & 59.0254 & 7.6828 \\
\hline A5 & 37.2175 & 21.6790 & 0.0242 & 0.0043 & 0.0921 & 0.0100 & 59.0271 & 7.6829 \\
\hline A617 & & & & & & & & \\
\hline A645 & 37.2147 & 21.6364 & 0.0249 & 0.0043 & 0.0921 & 0.0100 & 58.9823 & 7.6800 \\
\hline A646 & 37.2173 & 21.6762 & 0.0251 & 0.0043 & 0.0921 & 0.0100 & 59.0250 & 7.6828 \\
\hline A647 & 37.2179 & 21.6772 & 0.0250 & 0.0043 & 0.0921 & 0.0100 & 59.0266 & 7.6829 \\
\hline A648 & 37.2171 & 21.6812 & 0.0247 & 0.0044 & 0.0923 & 0.0101 & 59.0299 & 7.6831 \\
\hline A649 & 37.2175 & 21.6844 & 0.0247 & 0.0045 & 0.0924 & 0.0101 & 59.0336 & 7.6833 \\
\hline
\end{tabular}

Table 7: The distance of each alternative to the negative ideal solution

\begin{tabular}{|l|l|l|l|l|l|l|l|l|}
\hline $\begin{array}{l}\text { Product } \\
\text { sample }\end{array}$ & C1 & C2 & C3 & C4 & C5 & C6 & Sum & $S_{i}^{-}$ \\
\hline A1 & 17.2212 & 0.0012 & 0.0010 & 0.0004 & 0.0084 & 0.0000 & 17.2321 & 4.1512 \\
\hline A2 & 17.2192 & 0.0011 & 0.0010 & 0.0003 & 0.0083 & 0.0000 & 17.2300 & 4.1509 \\
\hline A3 & 17.2204 & 0.0012 & 0.0010 & 0.0003 & 0.0083 & 0.0000 & 17.2312 & 4.1510 \\
\hline A4 & 17.2191 & 0.0011 & 0.0010 & 0.0003 & 0.0083 & 0.0000 & 17.2299 & 4.1509 \\
\hline A5 & 17.2188 & 0.0012 & 0.0009 & 0.0003 & 0.0084 & 0.0000 & 17.2297 & 4.1509 \\
\hline. & & & & & & & & \\
\hline A617 & 17.2169 & 0.0009 & 0.0011 & 0.0003 & 0.0084 & 0.0000 & 17.2276 & 4.1506 \\
\hline. & & & & & & & & 17.2297 \\
\hline A645 & 17.2187 & 0.0011 & 0.0011 & 0.0004 & 0.0084 & 0.0000 & 4.1509 \\
\hline A646 & 17.2191 & 0.0011 & 0.0011 & 0.0004 & 0.0084 & 0.0000 & 17.2301 & 4.1509 \\
\hline
\end{tabular}




\begin{tabular}{|l|l|l|l|l|l|l|l|l|}
\hline A647 & 17.2186 & 0.0012 & 0.0011 & 0.0004 & 0.0084 & 0.0000 & 17.2297 & 4.1509 \\
\hline A648 & 17.2188 & 0.0012 & 0.0011 & 0.0004 & 0.0084 & 0.0000 & 17.2299 & 4.1509 \\
\hline A649 & 17.2187 & 0.0012 & 0.0011 & 0.0004 & 0.0084 & 0.0000 & 17.2296 & 4.1509 \\
\hline
\end{tabular}

Table 8: Calculation of the relative proximity

\begin{tabular}{|l|l|l|l|}
\hline Product sample & $S_{i}^{-}$ & $S_{i}^{*}$ & $C_{i}^{*}$ \\
\hline A1 & 4.1512 & 7.6835 & 0.350762 \\
\hline A2 & 4.1509 & 7.6825 & 0.350779 \\
\hline A3 & 4.1510 & 7.6831 & 0.350770 \\
\hline A4 & 4.1509 & 7.6828 & 0.350769 \\
\hline A5 & 4.1509 & 7.6829 & 0.350764 \\
\hline. & & & \\
\hline A617 & 4.1506 & 7.6800 & 0.035837 \\
\hline. & & & \\
\hline A645 & 4.1509 & 7.6828 & 0.350768 \\
\hline A646 & 4.1509 & 7.6829 & 0.350768 \\
\hline A647 & 4.1509 & 7.6831 & 0.350759 \\
\hline A648 & 4.1509 & 7.6833 & 0.350753 \\
\hline A649 & 4.1509 & 7.6828 & 0.350762 \\
\hline
\end{tabular}

\section{Conclusion}

In most cases quality classification can be considered as the multi criteria decision making problem included factors affecting quality. There are different methods for decision making problems to take decisions for many real time problems. TOPSIS is considered as one of the leading MCDM method that helps the decision makers to organize and carry out analysis to solve problems by comparing and ranking the alternartives (Shih, Shyur, \& Lee, 2007).

In this study, physical properties of ATY are the factors affecting the quality of the yarn. Count elongation, shrinkage, tenacity,RKM, breaking force are six criteria have most influence degree of standard quality.Ranking all samples as altenatives, from best to worst, will provide to make a classification of quality level of the yarn. Alternative 617 (A617) is the best best yarn sample which is the most close to the standard quality values and and can be marked at the hishest level of the quality classification. Alternative 470 (A470) is the worst altenative and can be marked at the lowest level of the quality classification. A comparision can be done between the any sample with standard quality values, according the ranking. Managers of the firm can be also hava a pricing strategy with the help of the quality classification, Yarns having the hishest level of the classification can be assigned as high-cost 
merchandise and that can be more profitable for the firm. Ranking also is useful to eliminate yarn faults at the quality conrol process before meet the customer.

The recommendations for future research are, to idetfy the weights of the criteria with a MCDM method and use other MCDM methods including weights of the criteria and based on ranking, to make a comparision between the results.

\section{References}

https://www.ucalgary.ca/fyke_war_rugs/files/fyke_war_rugs/carpet\%20weaving\%20elements .pdf adresinden alınmıştır

Acar, E., Kılıç, M., \& Güner, M. (2015). Measurement of sustainability Performance in Textile Industry by using a multi-criteria decision making method. Tekstil ve Konfeksiyon, 3-9.

Bathrinath, S., Bhalaji, R. K., \& Saravanasankar, S. (2020). Risk Analysis in textile industries using AHP-TOPSIS. Materials Today, 1-7.

Hwang, C. L., \& Yoon, K. (1981). Multiple Attribute Decision Making: Methods and Applications. New York: Springer-Verlag.

Majumbar , A., Kaplan, S., \& Göktepe, Ö. (2010). Navel selection for rotor sipinning denim fabrics using a muti criteria decision-making process . The Journal of The Textile Institute, 101(4), 304-309.

Özkan, S., \& Babaarslan, O. (2008). Effect of Fiber Cross-Section and Filament Linear Density on POY and Texturising Yarn Properties . Ç.Ü Fen Bilimleri Enstitüsü, 19-2, 147-160.

Saeidi, R. G., Amin, G. R., Raissi, S., \& Gattoufi, S. (2013). An efficient DEA method for ranking woven fabric defects in textile manufacturing. Int J Adv Manuf Technol, 349354.

Saeidi, R. G., Oukil, A., \& Amin, G. R. (2015). Prioritization of textile fabric defects using ordered weighted averaging operator . Int J Adv Manuf Technol, 745-752.

Shih, H. S., Shyur, H. J., \& Lee, E. S. (2007). An Extension of TOPSIS for Group Decision Making . Mathematical and Computer Modelling, 45(7), 801-813.

Sreenivasamurty, H., \& Prushothama, B. (2017). Texturising Defects Causes, Effects, Remedies and Prevention through Quality Management. New Delhi: Woodhead Publishing.

Subramaniya, K. P., Dev, C. A., \& SenthilKumar, V. S. (2017). Critical Success Factors : A TOPSIS approach to increase Agility Level in a Textile Industry. Materials Today, 1510-1517. 